\title{
Afinal, a Quem "Pertencem" as Especialidades Médicas?
}

$\mathrm{N}_{\mathrm{p}}^{\mathrm{o}}$

O EDITORial publicado na edição de Agosto de 2001, mencionei de passagem, e num outro contexto, que “... endocrinologistas senso lato têm-se incomodado com a invasão de seus pretensamente exclusivos domínios por outros especialistas (ginecologistas endócrinos, pediatras endócrinos, reumatologistas, nefrologistas, e até esteticistas e cosmetologistas) ..."

Neste número dos ABE\&M enfocamos uma área na qual não parece haver qualquer divergência a respeito da primazia do endocrinologista sobre outros especialistas: o diabetes mellitus e sua plêiade de manifestações clínicas. Trata de uma série de artigos originais, não encomendados, produzidos em diversos Centros de Assistência e Pesquisa do país, e traz respaldo para algumas considerações sobre o tema que passo a desenvolver.

$\mathrm{Na}$ verdade, é até temerário abordá-lo assim, sem maior elaboração; tampouco pode ser deixado para ser discutido apenas nos bastidores. Talvez este seja mesmo o timing mais adequado.

Quem pode responder às seguintes questões?: a glomerulosclerose intercapilar de Kimmelstiel-Wilson - base da nefropatia que compromete a função renal do paciente com diabetes -, deve ser acompanhada pelo endocrinologista ou pelo nefrologista? E a calculose renal devida a distúrbios do metabolismo do cálcio, do magnésio e do ácido úrico? Endócrinometabologistas, nefrologistas ou urologistas? Como ficam ainda a neuropatia, a vasculopatia e a retinopatia diabéticas? Atenção multidisciplinar, sem dúvida, mas cuidado primário de quem? Por que não dos homeopatas ou, quem sabe, dos recém-chegados orto-moleculares? (Aliás, o que vem a ser mesmo medicina orto-molecular?!).

A divergência ou ambigüidade persiste: osteoporose da menopausa (ou de qualquer outra causa) é uma condição que deve ser avaliada e tratada primariamente pelo endocrinologista ou pelo ginecologista? Ou pelo reumatologista? Quem sabe pelo ortopedista, quando a paciente é sintomática? Ou será que o clínico geral é suficiente?

Se além do especialista há um sub- ou super-"especialista" de determinada glândula, com seu produto hormonal específico (caracterizando a sub- ou super-especialidade), porque não haveria na outra ponta, um outro "especialista" do tecido, órgão ou sistema afetado pelo excesso ou falta daquele hormônio? Esta glândula e o(s) seu(s) hormônio(s) estão sob jurisdição exclusiva do endocrinologista somente quando afetam o organismo de maneira inespecífica, ou mesmo quando o alvo específico afetado "pertence" ao território do colega não endocrinologista?

No caso, o paciente acometido por esta condição virtual - que tem origem na glândula, mas afeta secundariamente outro(s) órgão(s) à distância -, merece ser tratado por quem? Por aquele que supostamente conhece a causa e os mecanismos que originaram o problema (endocrinologista) ou por quem teoricamente sabe controlar o órgão/tecido afetado? Antes de tudo, e por mais óbvio que seja, nunca é demais lembrar que causa e efeito não podem jamais estar dissociados; somente vistos assim, o diagnóstico e o tratamento serão precisos e específicos. 
A questão, entretanto, é pertinente: qual dos "especialistas" terá o melhor desempenho médico, proporcionando bem estar, conforto e segurança ao paciente, levando-se em conta os binômios risco-benefício e custo-efetividade? $\mathrm{O}$ endocrinologista julga-se possivelmente mais habilitado, já que está atento aos desarranjos que o "seu" hormônio pode causar; e sendo mesmo a "sua" glândula a origem e a culpada pelo distúrbio, estará sob sua responsabilidade e obrigação sanar o problema na fonte. A colocação pode parecer lógica, mas ... vejamos a outra ponta!

O "especialista" do órgão/tecido afetado pode até saber, mas por vezes nem desconfia que o problema pode estar sendo causado pelo hormônio (excesso ou falta) do seu colega. Até por que aquela manifestação, digamos que bastante prevalente, costuma ser apenas excepcionalmente causada por uma disfunção hormonal!

Existem incontáveis exemplos de condições de alta prevalência cujas causas específicas conhecidas são, entretanto, bastante incomuns. Assim, quantos gastroenterologistas suspeitariam de imediato que uma gastrite ou úlcera gastroduodenal (condição bastante prevalente) poderia resultar de hipercalcemia associada à secreção aumentada de paratormônio? ou de cortisol? (causas possíveis, mas raras). Quantos clínicos, cardio ou nefrologistas, frente a determinado paciente hipertenso, pensariam na possibilidade diagnóstica de hiperaldosteronismo primário ou feocromocitoma? $\mathrm{Ou}$ mesmo de acromegalia ou Cushing? Quantos ginecologistas e reumatologistas suspeitariam que uma paciente com osteopenia ou osteoporose poderia estar albergando um tumor de paratiróide (hiperparatiroidismo primário)? ou de adrenal (hipercortisolismo)? ou de hipófise (hiperprolactinemia com hipogonadismo)? Quantos ginecologistas ou dermatologistas suspeitariam que as alterações menstruais, acne e hirsutismo daquela adolescente obesa poderiam ser manifestações de hiperinsulinismo ou de hiperplasia adrenal congênita, forma não clássica (para não entrar na polêmica da síndrome dos ovários policísti$\cos$ )?. Quantos clínicos gerais e hematologistas pensariam, antes de tudo, em hipotiroidismo primário numa paciente com anemia, desânimo e sonolência? E mesmo que alguns, ou todos eles, suspeitassem correta e prontamente do diagnóstico, possivelmente não estaria sob seu domínio a melhor condução do caso.

São inúmeras as doenças ou condições clínicas de interesse comum (e, por extensão, de conflito) entre as várias "especialidades" médicas: além das já apontadas, não será demais lembrar as dislipidemias, as alterações psiquiátricas, a obesidade, os distúrbios hidro-eletrolíticos, a hipertensão arterial, as doenças endócrinas da infância e da adolescência, da mulher em suas várias fases (incluindo a gravidez e o climatério), dos idosos, dos esportistas, etc. A quem, de fato, "pertencem" as (sub-/super) especialidades médicas? Quem detem direitos sobre quais doenças? Quem estaria impedido de atender outras? A quem cabe decidir estas questões e dirimir as muitas dúvidas?

Vejo a contenda meio sem nexo, por exemplo, dentro de um hospital universitário ou de uma instituição pública de assistência e ensino médicos, uma vez que para cuidar de determinada condição de um paciente previdenciário existem pessoas capacitadas tanto em uma como em outra área médica. A interação, na verdade, costuma ser e será sempre proveitosa para todos. A situação muda substancialmente quando o interesse em jogo não é mais o mero exercício sagrado e honesto da profissão, mas a disputa, às vezes algo mesquinha, pelo paciente particular, pela possibilidade do desproporcional retorno financeiro, ou pelo fascínio da eventual projeção que possa ser oferecida casuisticamente na mídia e no cenário social. Estas são, porém, questões que merecem reflexão e discussão num fórum mais amplo.

Convém retornarmos ao nosso paciente virtual! Como é ele quem sofre as conseqüências (manifestações clínicas) do distúrbio hormonal e, no seu melhor juízo - geralmente formado pela orientação de outros leigos (a eterna conspiração dos vizinhos e colegas de trabalho) -, irá, com maior probabilidade, procurar o "especialista" do órgão/tecido que o está incomodando. O "especialista" consultado, por não ter a obrigação de ser "especialista" naquilo de que muitas vezes nem desconfia, perde a oportunidade do diagnóstico e do eventual encaminhamento corretos e trata o paciente de maneira inespecífica (às vezes inapropriada), ficando a resolução de todo o processo muito aquém do ideal. No final, o grande paradoxo é que aquele que mais sofre (o paciente) e menos culpa tem no processo (embora seja quem o tenha originado), acaba por ser o único derrotado.

Como isto parece ocorrer de maneira disseminada neste país, arrisco creditar a culpa à carência generalizada de campanhas oficiais de esclarecimento e à falta de divulgação à sociedade de informações mais precisas e abrangentes sobre questões específicas de saúde pública (quando não ao abuso de desinformações), promovidas por Sociedades Médicas com o apoio e o patrocínio do Ministério da Saúde.

Desta maneira - pensando sempre no benefício do paciente e do público em geral -, creio que devamos (nós endocrinologistas, pelo menos) estimular 
que lhes sejam oferecidas informações apropriadas, exatas, sensatas e profusas sobre doenças e condições de maior prevalência (diabetes, obesidade e osteoporose, por exemplo), para que possam, conscientemente, decidir pelo melhor caminho. Que sejam promovidas campanhas bem intencionadas e bem direcionadas, informando e, conseqüentemente, atraindo o paciente; por outro lado, que se impeça que a atenção do público seja desviada para informes desvirtuados e para a vasta (não sei porque ainda liberada) propaganda desonesta e enganosa que prospera nos mais variados meios de comunicação. A fluência, a desinibição e o bem vestir - características muitas vezes bastantes para exercer o fascínio e a atração de incautos -, são a rotina em programas de entrevistas na televisão mas, com mensagens muitas vezes superficiais e/ou distorcidas e quase nunca acompanhadas do aval e da chancela da Sociedade Médica de sua especialidade, não garantem a propaganda e o exercício de uma boa medicina. Que sejam feitas, portanto, em nome de nossa especialidade e por meio de nossa Sociedade, campanhas e discursos claros e honestos promovendo o conhecimento e assumindo responsabilidades. Aproveito para manifestar meu total apoio à campanha que a atual Diretoria da SBEM está iniciando (em âmbito nacional, em seqüência àquelas desenvolvidas com enorme sucesso no Distrito Federal e em outros Estados), de orientação, esclarecimento e atendimento ao público com relação às questões pertinentes à endocrinologia prática.

Mas, enquanto disputas, antigas e atuais, ocorrem em defesa do sagrado interesse profissional e econômico (fundamental para o exercício liberal da profissão), existe uma outra visão a ser considerada.

Nesta ótica, o lado mais salutar e vantajoso desta diversificação ocorre entre a comunidade de cientistas e pesquisadores. O interesse científico puro e descompromissado com as questões pertinentes ao exercício da profissão, faz com que a pesquisa e o desenvolvimento da medicina avance a passos firmes e largos, independente da "especialidade" na qual atue o pesquisador. Para ele ou ela, isto não parece fazer qualquer diferença. O importante é o simples encontro de respostas e soluções para determinadas questões e problemas. Esta atitude faz de congressos e reuniões científicas variadas, uma "Babel " de pesquisadores de áreas básicas diversas, endocrinologistas, nefrologistas, ginecologistas, neurologistas, pediatras, etc, sem qualquer preocupação (até pelo contrário) se há ou não interferência deste na área de atuação daquele. Quem nunca ganhou ao interagir com colegas de outras áreas através de seu conhecimento exposto em simpósios e conferências ou publicado em revistas médicas de outras especialidades? A bem da verdade a "competição" aqui também existe, mas é bem mais no estilo da disputa pela originalidade ou primazia de dados, e acrescenta ao invés de diminuir valores. Os prêmios, sob a forma de "grants" que irão financiar novos projetos de pesquisa, vão para os mais atuantes e para os mais capacitados, sejam desta ou daquela área.

Os editores de revistas científicas, por extensão, também se beneficiam muito com esta atitude. Além dos obstinados endocrinologistas, colaboradores de qualquer "especialidade", sejam pediatras, cardiologistas, urologistas ou odontólogos, serão sempre bem vindos para publicar suas contribuições em nossos ABE\&M, abordando temas e assuntos que possam interessar direta ou indiretamente ao endocrinologista. No geral, temos tido o privilégio de receber artigos de autores cujas áreas de atuação algumas vezes apenas tangenciam, mas muitas vezes interagem e se interligam com a nossa endócrino-metabologia.

Tudo isto tem sido muito gratificante, e não seria sensato coibir qualquer manifestação em contrário. Basta, evidentemente, não associarmos as duas questões apresentadas neste material. "Uma coisa é uma coisa, outra coisa é outra coisa", já disse algum colega do gramado! 